\title{
Discussion Article: Disciplinary Boundaries for Creativity
}

\author{
Stuart Rowlands \\ Centre for Teaching Mathematics, University of Plymouth, Plymouth, UK \\ Email: stuart.rowlands@plymouth.ac.uk \\ Received October 25 ${ }^{\text {th }}$, 2010; revised February 9 ${ }^{\text {th }}$, 2011; accepted February 23 ${ }^{\text {rd }}, 2011$.
}

\begin{abstract}
Creativity is a very topical issue and indeed a political one. For example, the very notion of 'little c creativity' seems to be a reflection of the requirements of what could be described as a 'Post-Fordist' economy. However, the call to develop creativity in education is largely based on the idea of creativity as the production of novel ideas. The central argument of this article is that creativity cannot be seen purely in terms of novel ideas but that it is intrinsically bound with the teaching of the academic disciplines. It is within the context of creativity in the sense of transforming the disciplines that two paradoxes are discussed. The first paradox is that the truly creative act is not the preserve of the genius but the potential for the whole of humanity. Secondly, creativity involves both thinking within the constraints of the discipline and challenging those constraints. This implies the need for students to engage in meta-discourse, involving the nature and history of the subject-matter taught.
\end{abstract}

Keywords: Art, Mathematics, Science, Novel Ideas, Transforming the Disciplines

\section{Introduction}

Although creativity in education was a concern that began in the 1950's (Craft, 2001a), this concern has become a highly topical issue over the past fifteen or so years. Recently in the United Kingdom there have been many conferences and meetings on creativity and education with input from museums and the arts and examples include the British Educational Research Association's Special Interest Group 'Creativity in Education', the Economic and Social Research Council's Creativity in Education Seminar Series, the National Advisory Committee for Creative and Cultural Education (NACCCE) and the plethora of books and articles on the subject. In all this interest, however, there is a tendency to promote creativity in terms of the creation of novel or innovative ideas that are independent of the teaching and the content of the formal academic disciplines such as mathematics, science, history and art. This paper argues the claim that the vast majority of humankind is capable of truly creative acts, not merely in the sense of novel ideas but also in the sense of transforming the very disciplines themselves. This is indeed a very bold and paradoxical claim because it states that what is normally attributed as acts of genius can also be attributed to nearly every learner. It is within this context that the further paradox between having to think within the constraints of the discipline and thinking creatively by rethinking those constraints is explored. This article's main concern is that if we ignore creativity in the sense of Boden's transformation of the subject matter of the disciplines then we will fail to unlock the creative potential of the child.

Section 1 begins with the boom in popularity of creativity and argues that the current discourse undermines what it is to be truly creative. Creativity has been reduced to the production of novel ideas separate from the learning of academic subjects. This section argues that no separation should be made between promoting creativity and the teaching of those subjects.

Section 2 discusses the link between creativity and intrinsic motivation. This section argues that creativity is a prime need of every human being, is incompatible with extrinsic rewards and that the whole of humankind is capable of being creative in the sense of being truly original.

Section 3 discusses how creativity in the transformative sense of changing the disciplines can be fostered. It shall be argued that such creativity requires learning and exploring the domain of knowledge comprehensively and, paradoxically, by playing with the constraints of the system of knowledge. This can be encouraged by a meta-discourse that reflects upon the nature of the theoretical objects the learner is expected to think in and work with. It will be argued that a cultural-historical approach can provide the stepping-stone to the relevant level of abstraction by immersing the learner in the relevant problem space. This section also discusses why an objectivist approach to creativity is fundamental compared with an inter- or intra-subjectivist approach and why, in terms of creativity, the teaching of science should not be reduced to making sense of experience (as there has been a tendency to do).

Section 4 discusses knowledge synonymous with mental representation and argues that creativity is a construction process involving rational insight, symbolic thought and metaphoric perception

\section{What Creativity Isn't: Creativity as Novel Ideas}

\section{The Ideology of Creativity}

Given the possible links between creativity and education and the implications that one has for the other - whether it be in terms of educational policy, curriculum development or classroom practice - the interest in creativity is not surprising. What does seem a little surprising, however, is its boom in popularity. Perhaps most educators would agree that the fostering of creativity in the classroom is a priority, but it would appear that this 
increase in the promotion of creativity has more to do with promoting the ability to be novel in an everyday context than with developing the potential to be creative within the disciplines. As Rowland (2009) states in connection with school mathematics, creativity can be an elusive and over-hyped notion.

Similar to the concepts paradigm and life-form, Creativity may not admit to being well-defined but having characteristics that can be discerned. In a negative article 'What Creativity Isn't' Gibson (2005) attempts to problematise the term by giving many examples of the various discourses in which the term is used. With reference to the UK he states:

Certainly it's a term now widely used, full of promise, a tonic for some after a decade of national over-governance of the school curriculum, a glimmer of hope and a word with which everyone can agree. Another hurrah word. (Gibson, 2005, p.148, emphasis added).

From the many examples given, Gibson identifies two emerging themes that have questionable assumptions: a romantic individualism of a bygone age with a Rousseau-like child-centeredness, and the future needs of the workforce. Gibson may well have hit upon the two underlying causes of creativity's popularity: creativity as an opportunity to advance learner-centred pedagogy (and, as will be shown, giving the opportunity to downplay the disciplines) and creativity as a necessity if British capital is to survive the global economy.

The two causes of creativity's popularity may be linked. Outside the content knowledge of the disciplines qua discipline but within the context of subject matter specifically related to the everyday, creativity becomes how the individual faces life's challenges and the requirement to foster a 'creative' labour force specific to the requirements of capital at any time. Having to survive the everyday also includes having to survive fragmented labour markets (which fluctuates. Studying for a degree in golf course management, surfing studies or perfumery courses that presently exists at some UK universities - may subsequently require the creativity of finding alternative forms of employment). For example, Craft (2001a) proposes the development of 'little c creativity' (LCC - the ability to think in novel ways in an everyday context) that would enable the individual to face the reality that we can no longer expect a job for life. Creativity thus becomes flexibility in response to the fragmented labour markets of what some may describe as the 'Post-Fordist' economy. The then Secretary of State for Education and Skills, Estelle Morris, stated:

The best employer knows that his future depends on the imagination and the creativity of his current workforce and of his future workforce. And it is innovation and creativity and risk taking that actually will give us economic prosperity and economic survival. The demand it puts on schools is different than it was before (Morris, 2002, p. 3)

Eight years hence and the employer's future has more to do with the current economic crisis than it has the imagination and creativity of his workforce. This raises the question as to whether schools should serve the interests of the employer or the educational interests of the learner. The then prime-minister, Tony Blair, might have responded that these two interests are the same in the sense that a healthy economy is necessary for healthy individuals; but with hindsight we can see that a creative workforce does not necessarily make a healthy economy. A
Marxist (e.g. Matthews, 1980), however, would argue that this interest in creativity reflects the need of capital to transform labour-power (the capacity and ability to do work) relevant to these fragmented labour markets, in addition to any concern for the individual to function in a society that is in crisis. For the Marxist we have a contradiction with respect to the emphasis on learner-centred pedagogy: The emphasis on LCC and the reduction of creativity to novel and innovative ideas independently of the disciplines may serve the interests of capital, yet it will also undermine the true creative potential of the vast majority of children with respect to learning the disciplines. It is this sense of creativity that will be explored throughout this article.

The educationalist who wants to foster creativity in the classroom may question the promotion of creativity for the market. For example:

But, how desirable is the norm of innovation that the global economy demands? To what extent is it desirable to encourage and sustain the 'disposable' culture, where obsolescence is built in at the design stage of many consumer goods? To what extent do we, in the marketplace at any rate, encourage innovation for innovation's sake and without reference to genuine need? (Craft, 2003, p.121).

The promotion of creativity in a global economy that cares more for rates of profit than it does people's needs might be unpalatable to the liberal or left-wing educator. Nevertheless, despite any good intention, to promote LCC might be in the long run to promote the economy of the nation state and hence to promote profitability for the employer rather than for people's needs.

\section{Creativity and the Subject Matter}

Creativity has become the banner for romantic individualism and this can be seen in the way many educationalists have promoted creativity as if it were bipolar to the content knowledge of the disciplines. For example:

Although some teachers or observers want to concentrate on a particular subject or type of classroom activity, others might wish to address a more overarching notion like 'creativity', or the extent to which children are able to use their imagination and ingenuity, irrespective of the subject being taught. (Wragg, 1999, p. 28, emphasis added)

Creative teachers are interested in knowledge, but they are more interested in skills and even more interested in attitudes and values (Lucas, 2001, p. 39).

From the creativity SIG at BERA's 2005 annual conference we have one speaker stating as a major theme of his presentation: "ambiguity is important". This is problematic with regards to the well-defined concepts of science and mathematics. The following speaker stated "It is better to be eclectic than to impose the disciplines" uttered within the context of listening to the child. Ironically, this could serve to undervalue the child: the promotion of creativity at the expense of knowledge content has the potential to create a two-tier system whereby the children of the rich will learn the disciplines (and, with quality teaching, learn how to become creative within it) and the children of schools in the state sector learn to become eclectic, such as learning consumer arithmetic as a creative life-skill and figuring out why the school pond has turned green.

The NACCCE (1999) report emphasises the need for a bal- 
ance between content knowledge and creativity as if this balance would satisfy Aristotle's golden mean. Sometimes, the importance of the former is referenced but subsequently ignored in the emphasis on the latter (e.g. Haigh, 2003; see section 3). An exemplar of this bi-polar view in practice is the UK National Curriculum for mathematics, whereby creativity is a 'requirement' but amounts to little more than the teaching of the content of the National Curriculum on the one hand and a few excursions into open-ended investigations on the other. This bi-polar view is consistent with the constructivist philosophy in mathematics education that emphasises the process of 'doing' mathematics (sometimes referred to as 'mathematization', e.g. Jaworski, 1994) while at the same time downplaying the learning of the content of mathematics (any emphasis on content deemed 'absolutist'). ${ }^{1}$ This section argues that creativity and content knowledge ought to be inseparable. If separated, creativity is reduced to novelty and content knowledge merely becomes something to be learnt - if at all.

This recent explosion of interest in creativity has tended to reduced creativity to the production of novel ideas, but this is not something new. Over the years there have been many different approaches to creativity (for an overview, see Craft, 2001b) and although diverse, many approaches have treated creativity in terms of ideas that are novel (Boden, 2001), such as, for example, books on how to develop your creative potential (e.g. Adams, 1988) or creativity tests that measure divergent thinking. According to Diakidoy and Kanari (1999), creativity has been traditionally defined in terms of a characteristic or cognitive process that results in a novel outcome and sometimes without reference to whether those ideas are right, wrong or relevant. Not surprisingly, the authors have found a tendency for student teachers to see creativity in terms of novel ideas that were not necessarily appropriate or correct. This seems to be quite consistent with the educational philosophy (e.g. radical constructivism) that emphases how the pupil conceptualises the problem or task as opposed to whether the pupil has correctly conceptualised the problem or task (e.g. Jaworski, 1994). Of course, creativity does involve novelty, but most approaches to creativity have focussed on novelty to the exclusion of the background knowledge that gives the novelty its meaning

\footnotetext{
${ }^{1} \mathrm{~A}$ critique of constructivism's notion of 'absolutism' can be found in Rowlands et al. (2010).

${ }^{2}$ According to Kneller (1965), creativity can be introduced into education in one of two ways, either by teaching creativity on its own and in its own right, or we draw on the creative potential in all the subject matter we teach. Dunbar (1997) goes so far as to ask how is creative thought possible if the notion of creativity is reduced to novel ideas, especially since people make so many reasoning errors in experimental tasks involving arbitrary concepts with no background knowledge. Cropley (1971) doubts whether creativity can be taught as a subject in the school curriculum at all, but that the teacher can develop 'divergent' heuristics by encouraging the finding of solutions through inquiry, curiosity, independence and the drawing together of domains of relevant experience: "Creative thinking occurs when the boundaries of the known are first mastered, through convergent processes, and then extended, by the application of divergent processes" (Cropley, 1971, p.29). According to Parnes (1970), there exists much research that shows that mastery of subject matter increases, along with creative ability scores, as a result of weaving creative problem solving into existing courses. Whether creativity in education is seen in terms of either a two-stage approach or an interweaving approach, Kneller (1965), Dunbar (1997), Cropley (1971) or Parnes (1970) made no separation between creativity on the one hand and subject matter on the other.
}

(Ward et al., 1997). To refer to an idea that is either inappropriate to the problem or resolves the problem incorrectly as 'novel', is to lose the meaning of novelty with respect to the problem. If it is possible to develop creativity amongst pupils independently of and without reference to the context and content of ordinary school learning then there is still the problem as to how they can use their creative abilities in the context of ordinary school learning (Adey \& Shayer, 1994). Conversely, in the absence of participation in mature cultural conversations, namely the disciplines, any developing potential for creativity has little to work with. For Ward et al (1997), creativity is not the formation of novel ideas as a single process but an outcome of several processes such as conceptual combination, conceptual expansion, metaphor, analogy and mental model construction. Creativity, they argue, cannot occur without some meaningful link to what has come before, that is, prior knowledge has an overwhelmingly powerful role in creative endeavours. ${ }^{2}$ Prior knowledge, that is, in the sense of academic knowledge, not everyday knowledge.

Although this article argues that creativity should not be reduced to the formation of novel ideas, the individual who can formulate novel ideas that are appropriate and correct with respect to the subject domain can be said to manifest creativity. The ideas formulated may only be novel with respect to his or her own understanding of the subject; in other words, the ideas may have been thought of before by someone else, so the ideas are not truly novel. Nevertheless, the construction of a conceptual understanding of a subject domain, as opposed to the memorisation of rule-of-thumb procedures, manifests the conditions for development towards creativity. For example, the pupil in mechanics who changes her conception of force and motion from what may be described as an Aristotelian notion to a Newtonian one manifests creativity (see Carson \& Rowlands, 2005). To think of problems concerning force and motion within possible world contexts of frictionless surfaces or where gravity can be an option, without resorting to casting the problem algebraically, is to think in a creative context. The teacher who invites the class to think in terms of possible worlds: 'How would you set in uniform motion a puck resting on a frictionless horizontal surface?' or 'Gravity is switched off and I throw a ball in the air. Describe its motion' (see Carson \& Rowlands, 2005), has created the conditions for creative development whereby the class uses its imagination but is constrained to think within the domain of the subject. This is elaborated further in the section after next.

\section{Creativity and Intrinsic Motivation}

Creativity requires work, either in learning a skill or an academic subject, which is suggested by the old saying that creativity is $1 \%$ inspiration and $99 \%$ perspiration. The $99 \%$ perspiration also suggests learning through intrinsic motivation. Despite the tendency in much of the literature to reduce creativity to novel ideas, there is also the support for the 'intrinsic motivation principle of creativity’ (see Hennessey \& Amabile, 1988). For example, Cropley (1971) states that "material which is learned because it is in itself satisfying to the student's curiosity and ingenuity, and which is seen as a challenge to the learner's mental agility, needs no external rewards and punishments to keep the learning process in motion.” (p. 82). Amabile (1983) argues that intrinsic 
motivation is conducive to creativity whereas the extrinsically motivated state can be detrimental. This is supported by Bohm and Peat (2000), who argue that creativity is actually incompatible with external and internal rewards and punishments which are arbitrary requirements extraneous to the creative activity itself. They make the point that if creativity is made subservient to external rewards then the whole activity involved degenerates into something mechanical and repetitious. Of course, the pupil may want to learn for external reasons such as to pass an examination or please the teacher, or whatever, and the teacher may teach with respect to the class passing an exam to the best of their ability. However, to teach the subject in a way that develops the awe and intrinsic motivation of the pupil for the subject is the real challenge facing the teacher (which, ironically, may well develop the ability to do even better in examinations).

According to Bohm (1998), creativity involves the act of learning for its own sake, which is not to be confused with rote learning. "Creativity is a prime need of a human being and its denial brings about a pervasive state of dissatisfaction and boredom” (Bohm and Peat, 2000, p.232) and the biggest struggle in overcoming this pervasive state would be to convince most people that they are capable of being creative:

Most people, however, tacitly suppose that they do not have the necessary passion and courage to act in a truly creative way and are doomed to forever 'play false' with the more subtle features of their knowledge. They believe that, not being geniuses, they are restricted to the tacit infrastructures of subliminally held ideas. But suppose that this assumption is false, and that everyone is potentially capable of truly creative acts in various fields that accord with his or her particular abilities, skills, and knowledge. Clearly a prerequisite for this creativity is that we must cease to take for granted that we are incapable of creativity. (Bohm \& Peat, 2000, p. 51, emphasis added)

The reduction of creativity to novel ideas independently of the subject matter seems to rest on the tacit assumption that the vast majority of us are incapable of truly creative acts in the sense outlined. As stated above, this paper takes a more optimistic (and paradoxical) view that nearly all of us are capable of truly creative acts that are normally attributed to the genius.

For the teacher to draw on the creative potential of the learner is not to imply that creativity is innate in the sense that some people are and some are not creative. What it does imply is that anyone can become creative in the sense that we all have that potential. Creativity may well be a possibility for all, just as all chess players, according to Hestenes (1992), could become masters if only they would reflect on the reasons why they lose. Encouraging pupils to reflect so as to engender creativity will be explored in the next section. The point here is that creative quality is not the preserve of the genius but can reside in any kind of human activity and can be present in many different levels of ability or intelligence (Lytton, 1971). In art, for example, different but conventional forms of representation operate across a wide spectrum from children's' art to famous artists (Gombrich, 1996) and originality is possible for anyone at any level of representation. One prerequisite for originality is the inclination not to impose preconceptions on the facts as they are seen - a principle that is common to the whole of humanity (Bohm, 1998) to which Bohm includes children learning to walk and talk just by trying something out and seeing what happens. As eloquently expressed by Boden: "The creative thinker (potentially, every one of us) has the ability not to be rigorously limited by the pre-existing rules. But that is not to say that the rules are irrelevant (Boden, 2001, p.97, emphasis added).

If the majority of people have the potential to become truly creative in the sense of the scientist, then with respect to developing creativity in the classroom it may be insightful to ponder the awe and motivation of the creative scientist. For Bohm (1998): the scientist searches for something new that had previously been unknown, but this search has a certain fundamental kind of significance, a hitherto unknown lawfulness in the order of nature, which exhibits unity in a broad range of phenomena. Thus, he wishes to find in the reality in which he lives a certain oneness and totality, or wholeness, constituting a kind of harmony that is felt to be beautiful. In this respect, the scientist is perhaps not basically different from the artist, the architect, the musical composer, etc., who all want to create this sort of thing in their work. To be sure, the scientist emphasizes the aspect of discovering oneness and totality in nature. For this reason, the fact that his work can also be creative is often overlooked. But in order to discover oneness and totality, the scientist has to create the new overall structures of ideas which are needed to express the harmony and beauty that can be found in nature. (Bohm, 1998, p. 2, emphasis given)

Perhaps we can 'open the eyes' of the child to the oneness and totality of nature before we teach the structures of ideas that would enable the child to understand nature and to eventually express that oneness and totality. 'Opening the eyes' could begin in the first couple of years of schooling by providing an environment similar to the 'creative school' in Jeffrey and Woods (2003). Subsequently, immersing pupils in the relevant conceptual space and introducing them to the history of ideas that generated the conceptual space may help to develop that intrinsic awe and motivation. This is discussed in the next section.

\section{Creativity, Instruction and the Generative Structure}

\section{The Cultural-Historical Approach}

Mental development is dependent 'from the outside in' (Bruner, 1974) which is to say that, despite innate abilities, mental development is dependent on learning processes which are in turn related to instruction. According to Vygotsky (1978), learning processes are not synonymous with mental development but consist of the former leading the latter. Creativity in art, for example, is not a natural process that requires little or no teaching and practice - people have to learn to draw. Gombrich (1960) demonstrates how culture enables the construction of art by providing the necessary symbolic codes and schemata. The implication for the art teacher is that her class has to be enculturated into these symbolic codes and schemata prior to any possibility of the class becoming creative. How can the teacher do this? One possibility is an historical-cultural approach whereby the class examines the work of predecessors. For any discipline, the pupil reliving those cultural conversations that gave rise to the subject matter can become part of the creative process.

A truly creative idea, not one that is merely novel but innovative with respect to a background of ideas, does not come out of the void; it must rely on the insights of predecessors. Gombrich (1960) gives many examples, one of which is Con- 
stable whose paintings appear to 'mirror' reality as if he copied faithfully one-to-one what he actually saw - yet his style was developed from Cozens' study of clouds and Dutch seventeenth century landscape paintings. This suggests a point by Bohm and Peat (2000) that the 'inward perception' of the artist or scientist is affected by everything that the artist or scientist holds important about the history of art or science. An example by Bohm and Peat is Manet's 'Olympia' which owed much to Goya's 'The Naked Maja' and, in turn, inspired Cézanne to paint 'A Modern Olympia'.

To be aware of the history of something is to be aware that nothing is 'given' as such - that is, to be aware of development as human ingenuity to which one can belong. An awareness of the history of ideas as well as the ideas themselves can encourage a meta-discourse of those ideas, such that the pupil can become part of the creativity that was originally involved. A meta-discourse may encourage the pupil to think about the theoretical objects of the subject matter as well as thinking within those theoretical objects. This elaborates the point made earlier that creativity can be engendered by encouraging pupils to reflect upon their ideas in relation to the subject matter. For example, when asked 'what forces act on a thrown ball?' many pupils will respond that in addition to gravity and air resistance there has to be a force pushing the ball in order to overcome gravity. The teacher can respond by saying 'that is not the right answer but it is a good answer because that was the answer given by Aristotle and accepted for two thousand years until challenged relatively recently by Galileo' etc. The teacher can then invite the class to consider thought experiments similar to Galileo's so as to reflect upon and reconsider their initial response. This has nothing to do with any recapitulation theory, but learners at nearly all levels of development can relive those cultural conversations and if immersed in the relevant problem space can become part of the creative process that transformed the discipline in the first place.

An historical-cultural approach is a possibility in developing creativity because it provides the opportunity for reflection on the concepts of a formalised system. For example, as well as applying the 'rules' of mechanics, pupils can understand where those rules came from and develop a qualitative as well as a quantitative understanding of those rules. The people that were involved in the creation of these formalised cultural systems were creative people and if we, as educators, are to work towards developing this kind of creativity then it may be instructive to examine the creative person, not in terms of personality traits, idiosyncrasies, dispositions and the like, but in terms of what it is about them that is creative in terms of the subject matter.

\section{The Creative Person}

According to Gardner (1994), the creative person has two counteracting tendencies: one of scepticism that challenges assumptions and rejects conventional wisdom and one that explores a domain of knowledge comprehensively and deeply to the point of exhaustion. This suggests that if all or nearly all people have the potential of becoming creative then perhaps these two counteracting tendencies should be encouraged in the classroom. The first tendency implies giving the pupil the right to demand a reason for something, for example, why is Pythagoras' theorem how it is, and this can encourage critical thinking. The final authority residing in the discipline itself: that something is the case is not because the teacher, or indeed the academic community, says so (the fallacy of the argument by authority). The second tendency is encouraged by teaching the domain of knowledge in a way that the class 'makes it their own' (internalisation). Of course, an over packed curriculum may make this very difficult, but developing a conceptual understanding is shorter in the long run than memorising 'rule of thumb' procedures (Skemp, 1976). ${ }^{3}$ Creativity requires the development of critical thinking, but the conceptual space has to be thoroughly explored prior to any creative transformation of it (Boden, 1994b).

\section{The Generative Structure}

Understanding creativity requires understanding the generative structure - the conceptual space - that makes creativity possible. For Boden (1994b), the study of creativity requires asking the sort question that involves the structure of a generative system, such as 'Could that be proven using this method?' 'Is that a sonnet?' Generative systems include the rules for chess, the axioms for a vector space, the axioms of the Newtonian system, the schemata of the impressionists, grammar, a rhyming schema for sonnets etc. Questions about the generative processes involved (e.g. what inspired $\mathrm{X}$ to come up with $\mathrm{Y}$ ) has to make reference to the generative system:

A merely novel idea is one that can be described and/or produced by the same set of generative rules as the other, familiar, ideas. A genuinely original or radically creative idea is one that cannot. It follows that the ascription of creativity always involves tacit or explicit references to some specific generative system. (Boden, 1994b, p.78. emphasis added).

The exploration of a conceptual space can lead to novel ideas, but a novel idea can be said to be truly creative if it transforms the conceptual space. According to Boden (1994b), constraints are necessary for creativity and dropping a constraint can be a general heuristic for transforming a conceptual space (her examples include Schoenberg dropping the home-key constraint to create the space of atonal music and the dropping of Euclid's fifth axiom resulting in the development of non-Euclidean geometry). This dropping of a constraint is compatible with Johnson-Laird's (1988), 'non-determinism' - creativity as depending on arbitrary choices but also on the criteria or constraints of the framework. This tension between freedom and constraint in the development of creativity is a paradox facing the educator: "On the one hand, they must train logical, rational thought; on the other, they must foster fluency and freedom of mind and the ability to tap the springs of the creative subconscious. Mental discipline vs. mental freedom: in every classroom a balance must somehow be struck. The more we know of creativity, both its scope and its limits, the more enlightened this balance will be." (Kneller, 1965, p.79/80). ${ }^{4}$

In many respects the problem of creativity and the problem of free-will are one and the same in that they can both be solved together (Johnson-Laird, 1988). What gives us freedom of will but which occurs in acts of creation, according to Johnson-Laird, is the ability to reflect about how we shall make a decision and thus to choose at a meta-level of choice. For

${ }^{3}$ Skemp's, 1976, distinction between relational understanding and instrumental understanding in the learning of mathematics expresses this eloquently. 
Johnson-Laird, creativity on the one hand depends on arbitrary choices as opposed to deterministic procedures yet, on the other hand, creativity in art is carried out within the conventions of an existing genre and creativity within science normally occurs within the constraints of an existing paradigm.

The reference to the generative system involved is crucial if we are not to overstate any claims regarding generative processes. This is certainly true in the history of ideas. For example, scientific theories often have consequences that were unforeseen and unintended by the original proponents of the theory (Chalmers, 1982). Chalmers cites the example of Maxwell's introduction of the concept of a displacement current to Faraday's concept of an electric field - the consequences of which, that is, the prediction of radio waves, was not realised by Maxwell and not realised by the community until two years after Maxwell's death. This is not to undermine the creativity of such a move, or indeed to undermine the genius of Maxwell, but just how fruitful a creative move is can only be ascertained with reference to the generative system itself. Another example is Sacchieri, who, without realising the significance of what he had done, had contributed to the proof of a number of theorems to an entirely new type of geometry (Barker, 1964). In other words, the study of creativity requires an analysis of the development of the discipline, as a generative system, prior to any analysis of the psychology of the creativity of the individual concerned and prior to any analysis of the intersubjectivity of the relevant community (Chalmers, 1982). Subjective or inter-subjective considerations ought to be in the light of objective considerations - that is, the body of knowledge, the claims that it makes, its logical structure, its theoretical objects etc. ${ }^{5}$

\section{The Need for Educators to Understand the Genera- tive Structure}

Without understanding the structure of a conceptual space, any notion of creativity becomes redundant or reduced to the creation of novel ideas. Put another way, if educators do not understand the nature of the discipline to be taught, then they cannot advise on developing creativity within the context of the discipline. For example, in the book 'Creativity across the Curriculum', Hodgson (1980) describes science as beginning with observation using enhanced senses from which information is

\footnotetext{
${ }^{4}$ Interestingly, Kneller's book was written during the post-reform period in mathematics education when 'modern mathematics' and a progressive education that encouraged a more child-centred pedagogy replaced the rote learning of Euclid's Elements. Kneller argued that the educational system has neglected or suppressed the natural creativity of the young but prophetically stated: Although in the past education has neglected creativity, it would be folly to go to the opposite extreme and extol it to the detriment of mental discipline and mastery of subject matter. Advocates of creativity who call, for example, for "permissive"' and "creative" classrooms are really recommending that we subordinate formal education to the development of creative thinking. Yet such a subordination is inimical not only to education but also to creativity itself, for successful creation demands both material for the imagination to work on and techniques for transforming that material into realized form. Sound creativity, in short, presupposes mental discipline through mastery of subject matter. As Whitehead has said, "Education must essentially be a setting in order of a ferment already stirring in the mind", a setting in order that proceeds from the nature of the subject matter itself. (Kneller, 1965, p. 88)
}

gathered and generalisations made. This empiricist description of science has become quite prevalent amongst constructivist educators (for example, the New Zealand science curriculum discounts subject-matter competence for 'making sense of the world'. See Matthews, 1995) yet it offers no insight into science and creativity. If science is based on observation then the scientific revolution would not have began in the 1600's but within the great civilisations of thousands of years ago. The hallmark of science is abstraction, involving the construction of theoretical objects relevant to their respective domains, it is not the observation of physical objects: "The semantic reference of physical theories is not constituted by the objects perceived by direct observation, but by ideal objects which, in their reciprocal links, form the so called 'physical models'." (Lombardi, 1999, p. 222). Indeed, observations are theory laden (Chalmers, 1982) and no scientist performs an experiment without some theoretical point in mind (Toulmin, 1967). The implication is that to understand how creativity is possible within science is to understand the abstract nature of science and how this abstraction can model the real world (which is suggested by Hestenes', 1992, argument that experimental 'games' are model deployment 'games'). Indeed, Galileo was heavily criticised by his Aristotelian colleagues because his theoretical ideal pendulum, through which he elucidated the laws of nature, implied perpetual motion and real pendulums do not conform to this (see Matthews, 1994, chap. 6). The teacher therefore has to thoroughly understand the abstract nature of science if she is to encourage creativity in science lessons. Consider the following:

The purpose of this chapter ['Getting Meaning from Experiences: the Child and Science'] is to persuade such teachers [with little formal science education themselves] that (a) they have already a considerable knowledge of the science required, and (b) many of them have probably been teaching science, without necessarily being aware of the fact, by identifying some appropriate [sic] science objectives and illustrating ways in which they may be achieved. (Hodgson, 1980, p. 133)

Hodgson is creating a fallacy and an excuse for science teachers to be ignorant of science. A teacher who is not an expert in the subject matter cannot begin to develop creativity amongst the pupils with respect to the subject matter. Indeed, the teacher should not only be an expert with respect to what is taught, but should also be a philosopher and an historian of the subject and be able to engage the pupils in a meta-discourse concerning the concepts involved. That is a daunting challenge for the science teacher, but there really is no other option. To regard 'Big C Creativity' (creativity in the sense of Boden's transformative creativity) as 'elitist' and to push for Craft's 'Little C Creativity' ('democratic creativity') in the teaching of science (e.g. Haigh, 2003) may result in not actually teaching science. Within the context of New Zealand's science curriculum, Haigh (2003) has downplayed the learning of content knowledge for the 'three Ps of science' (problem posing, problem solving and peer persuasion). The 'three Ps of science' is not unique to science and fails to capture the nature of science. Haigh's investigative approach in the learning of science becomes vacu-

\footnotetext{
${ }^{5} \mathrm{~A}$ sociological theory of knowledge that does not take the content of knowledge into consideration would be unable to ascertain just how creative an idea in the body of knowledge is or can be (a critique of the sociology of knowledge of the Edinburgh Strong Programme can be found in Phillips, 1998).
} 
ous if investigation is independent of the theoretical constructs of the relevant domain (such as gene, force, electron, latent heat). Such an investigative approach is a form of what Matthews (1995) describes as sensism (or what Carson and Rowlands, 2005, describe as naïve empiricism). Another example is given by Leach (2001), whereby pupils pose and discuss their own questions entered into a database concerning the cockroach observed in a lab. Questions such as 'can roaches learn' and statements such as 'I think that roaches can learn, since our Madagascan giant roaches have learned that if they fall on their backs they can wave their legs and we will help them” (p.187), has more to do with making sense of appearances than it has with scientific reasoning. There is no evidence of the teacher or indeed of any pupil asking the question as to how we can disprove such a statement. In this example, scientific understanding appears to be a reduction to consensus established by the pupils - without reference to any scaffolding by the teacher with respect to the theoretical concepts of biology. This is not science in the sense of a body of knowledge that has developed since the scientific revolution. The 'science' of the teacher who has little or no formal science, the very notion of a 'children's science', pupils posing their own questions about the world and arguing for a consensus, data collection and trying to make sense of the data, is not science. If there is no science, then there can be no scientific creativity.

\section{Creativity, Symbolic Thought and the Educational Implication}

Creativity that involves original insight, argues Bohm (1998), has to do with both rational insight as well as the formation of new kinds of mental images. Rational insight involves the perception of key questions that help to indicate some of the contradictory or confused features of previous accepted general ways of thinking (Bohm, 1998). Rational insight usually presents a challenge to what is considered 'viable' and if the potential for original insight is to be promoted then knowledge must not be seen as making sense of experience. This is simply because the structure of a discipline may be totally different to what the pupil sees as 'viable'. The hundreds and if not thousands of academic papers on pupil 'misconceptions', 'preconceptions', 'alternative conceptions', or 'intuitive ideas' of scientific concepts such as force and motion are testament to the difference between 'viability' (e.g. a held and cherished 'misconception' of force and motion) and knowledge (e.g. force as defined and understood within the Newtonian system). If symbol and metaphor are involved in the process of rational insight, but knowledge becomes synonymous with 'mental representation' (e.g. von Glasersfeld, 1995), then that process will not be understood (a critique of making synonymous knowledge with mental representation can be found in Rowlands and Carson, 2001).

Metaphoric perception, according to Bohm and Peat (2000), is fundamental to all science and in perceiving a new idea in science the mind is involved in a similar form of creative perception as when it engages a poetic metaphor. Whereas the latter may remain relatively implicit, in science the meaning of the metaphor has to be made explicit with a more 'literal' detail (Bohm and Peat, 2000). Innovative ideas are the terms in which theories are conceived and give rise to specific questions which are articulated only in the form of these questions - a constructive process in which symbolisation, the essential act of thought, is the key to that process (Langer, 1957). For example, any question concerning force and motion in Newtonian mechanics has an implicit structure which determines the answer according to the laws of motion:

Mechanics determines one form of description of the world by saying that all propositions used in the description of the world must be obtained in a given way from a given set of propositions - the axioms of mechanics. It thus supplies the bricks for building the edifice of science, and it says. 'Any building that you want to erect, whatever it may be, must somehow be constructed with these bricks, and with these alone'. (Wittgenstein, 1974. proposition 6.341, p. 68).

To ask any question in mechanics is to invite an answer structured by the axioms, but it usually invites an intuitive response ('misconception'). In mechanics, force is the fundamental unit of analysis and is symbolic of the interaction between objects. The symbol is invariant to the many different forms of motion, all of which can be explained according to the axioms. For many students, however, force is contextualised according to how the motion is perceived (e.g. for a ball going up, there must be a force pushing it to overcome gravity). The shift from having an intuitive response to force to understanding its symbolic function (invariant to the different forms of motion) is a constructive process aided by how the axioms apply. To think according to those axioms requires a creative leap from intuitive 'misconceptions' to understanding impossible idealised worlds structured by the axioms as a way of explaining the real one. That shift can be said to be transformative, if only in relation to the learner. To teach in a way that creates that shift will have created the possibility for creative development in the transformative sense.

Symbolic thought makes provision for the interpretation of the facts, even those we don't anticipate from unexpected problems posed by nature (Cassirer, 1962). This is not to say that every kind of thought can cover the whole of reality (as Bohm and Peat, 2000, states: "if reality were ever to cease to show new aspects that are not in our thought, then we could hardly say that it had an objective existence independent of us", p.8). Nature has a habit of revealing the limitations of our thought (exemplified in Newtonian mechanics with non-macroscopic objects and objects at high velocities). Those limitations, however, have to be reached, requiring the necessary complex range of skills embedded in symbolic thought. The creative act in the transformative sense may require disgorging ensembles of symbolic thought from their original contexts to other novel contexts within the parameters of their constraints (which may also include the dropping of a constraint in the transformation of a conceptual space).

There are many historical examples in science that can serve to contextualize, for pupils, their intuitive notions and to understand fundamentally what science is - that is, to understand the intricate relationship between what is given empirically by Nature, what is derived logically from reason and what has been contributed by the artistic genius of some scientist in the form of a strategic 'convention' of thought (a formula, a model, an idealisation, an analogy, a metaphor or some other conceptual heuristics Carson and Rowlands (2005)). Immersing learners in the relevant problem space structured by the symbolic 
thought that transformed the very discipline not only creates the possibility for understanding the nature of science but also the possibility to become creative within science.

\section{Conclusion}

Creativity is not the same thing as knowledge, but is firmly grounded in it. What educators must try to do is to nurture the knowledge without killing the creativity (Boden, 2001, p. 102, emphasis added).

This article has taken a rather dim view of much of the current literature on creativity, but there is much scope for optimism, especially since the emergence of a number of articles that view creativity in the context of the disciplines. For example, according to Brinkmann and Sriraman (2009) some parts of the creativity literature have identified five principles concerned with creativity: The Gestalt principle (the need for gifted learners to consider problems over a protracted time period in the classroom); the free market principle (the taking of risks and the need to defend solutions to problems); the scholarly principle (the debating of certain historical approaches that helped transform the subject); the uncertainty principle (how the history of the subject can reveal the uncertainty of finding solutions) and the aesthetic principle (the aesthetic appeal of a 'beautiful' idea that unifies disparate ideas). Although a minority, such research shows what creativity should mean and therefore ought to be encouraged, as opposed to the plethora of articles that appears to support the creativity of the child but will in fact fail to unlock any truly creative potential that the child - indeed any child - might have.

Section 1 attempted to show that the divorce made between creativity and subject matter, that this bipolar view of creativity and content will render creativity as a political plaything rather than what the child, any child, may be capable of. Section 2 attempted to highlight the importance of intrinsic motivation in relation to creativity and section 3 argued that educators and teachers must understand the subject as a generative structure and find ways to engage the class with that structure. This engagement requires a meta-discourse between teacher and class and section 4 elaborates on how creativity in the classroom relies on making conscious symbolic thought as a cultural convention. All this is quite consistent with Vygotsky's point that instruction has to proceed ahead of development if it is to lead it, which means that the teacher who has embodied the subject matter can 'arouse the mind to life' by creating a cognitive response to the subject matter. This way, the learner can internalise the subject matter and become creative within it.

How can the teacher create a cognitive response? The answer has to be 'by engaging the pupil with the subject matter' and examples might include asking questions that demand a qualitative (conceptual) response (rather than simple recall or 'guess what's in my head' games), the giving of cues, prompts and hints for consideration and the raising of 'epistemological obstacles' that gave rise to the subject matter in the first place. In short, engaging the pupil with a meta-discourse (for a full discussion of metacognition in this context see Rowlands, 2009). Of course, certain concepts have to be defined, explained, elaborated etc. but the learner has to become engaged with the way these concepts are related. The subject matter cannot be simply 'transmitted' as such, but constructed by the learner under the guidance and direction of the teacher. Independently of specific training programmes, the facilitation of creativity in the classroom will be dependent on how the teacher structures the educational environment that makes it conducive to creativity (Diakidoy \& Kanari, 1999, emphasis added) and the structure should include the opportunity for meta-discourse - involving the nature of the subject and its history.

\section{References}

Amabile, T. M. (1983). The social psychology of creativity. New York, NY: Springer-Verlag.

Adams, L. J. (1988). The care and feeding of ideas. London: Penguin.

Adey, P., \& Shayer, P. (1994). Really raising standards: Cognitive intervention and academic achievement. London: Routledge.

Barker, S. F. (1964). The philosophy of mathematics. New Jersey: Prentice-Hall.

Bohm, D. (1998). On creativity. London: Routledge.

Bohm, D. and Peat, F. D. (2000). Science, order, and creativity (Second ed.) (first published in 1987). London: Routledge.

Bruner, J. (1974). Beyond the information given. London: Allen and Unwin.

Boden, M. A. (1994a). Introduction to dimensions of creativity (M. A. Boden, Ed.). London: MIT.

Boden, M. A. (1994b).What is creativity. In M. A. Boden (Ed.), Dimensions of creativity. London: MIT.

Boden, M. A. (2001). Creativity and knowledge. In A. Craft, B Jeffrey and M. Leibling (Eds.), Creativity in education. London: Continuum.

Brinkmann, A., \& Sriraman, B. (2009). Aesthetics and creativity: an exploration of the relationships. In B. Sriraman and S. Goodchild (Eds.), Relatively and philosophically ernest: festschrift in honor of paul ernest's $65^{\text {th }}$ birthday. Charlotte, NC: Information Age Publishing.

Carson, R., \& Rowlands, S. (2005). Mechanics as the logical point of entry for the enculturation into scientific thinking. Science \& Education, 14, 473-492. doi:10.1007/s11191-004-1791-9

Cassirer, E. (1962). An essay on man: An introduction to a philosophy of human culture (first published in 1944). New Haven: Yale University Press.

Chalmers, A. (1982). What is this thing called science? (2rd ed.) Milto n. Keynes:The Open University Press.

Craft, A. (2001a). Little c creativity. In A. Craft, B Jeffrey and M. Leibling (Eds.), Creativity in education. London: Continuum.

Craft, A. (2001b). An analysis of research and literature on creativity in education. Report Prepared for the Qualifications and Curriculum Authority.

http://www.ncaction.org.uk/creativity/creativity_report.pdf

Craft, A. (2003). The limits to creativity in education: Dilemmas for the educator. British Journal of Educational Studies, 51, 113-127. doi:10.1111/1467-8527.t01-1-00229

Cropley, A. J. (1971). Creativity. London: Longman Education Today Series.

Diakidoy, I. N., \& Kanari, E. (1999). Student teachers beliefs about creativity. British Educational Research Journal, 25, 225-243. doi:10.1080/0141192990250206

Dunbar, K. (1997). How scientists think: on-line creativity and conceptual change in science. In T. B. Ward, S. M. Smith and J. Vaid (Eds.), Creative thought: An investigation of conceptual structures and processes. Washington DC: American Psychological Association. doi:10.1037/10227-017

Gardner, H. (1994). The creators patterns. In M. A. Boden (Eds.), Dimensions of creativity. London: MIT.

Gibson, H. (2005). What creativity isn't: the presumptions of instrumental and individual justifications for creativity in education. British Journal of Educational Studies, 53, 148-167. doi:10.1111/j.1467-8527.2005.00288.x

Gombrich, E. H. (1960). Art and illusion. London: Phaidon. 
Haigh, M. (2003). Fostering creativity through science education: A case for investigative practical work. Paper presented at the British Educational Research Association 2003 conference. Edinburgh: Heriot-Watt University.

Hennessey, B. A., \& Amabile, T. M. (1988). The conditions of creativity, In R. J. Sternberg (Eds.), The nature of creativity: contemporary psychological perspectives. Cambridge: Cambridge University Press.

Hestenes, D. (1992). Modeling games in the newtonian world. American Journal of Physics, 60, 732-748.doi:10.1119/1.17080

Hodgson, P. (1980). Getting meaning from experience: The child and science. In M. Poole (Ed.), Creativity across the curriculum. London: George Allen and Unwin.

Jaworski, B. (1994). Investigating mathematics teaching: A constructivist enquiry. London: Falmer.

Jeffrey, B., \& Woods, P. (2003). The creative school: A framework for success, quality and effectiveness. London: RoutledgeFalmer. doi:10.4324/9780203437223

Kneller, G. F. (1965). The art and science of creativity. London: Holt, Rinehart and Winston, Inc.

Johnson-Laird, P. N. (1988). Freedom and constraint in creativity. In R. J. Sternberg (Eds.), The nature of creativity: contemporary psychological perspectives. Cambridge: Cambridge University Press.

Langer, S. K. (1957). Philosophy in a new key: a study in the symbolism of reason, rite, and art (first published in 1942). Mass: Harvard University Press.

Leach, J. (2001). A hundred possibilities: creativity, community and ICT. In A. Craft, B. Jeffrey and M. Leibling (Eds.), Creativity in education. London: Continuum.

Lombardi, O. (1999). Aristotelian physics in the context of teaching science: A historical-philosophical approach. Science \& Education, 8, 217-239. doi:10.1023/A:1008641526822

Lucas, B. (2001). Creative teaching, teaching creativity and creative learning. In A. Craft, B Jeffrey and M. Leibling (Eds.), Creativity in education. London: Continuum.

Lytton, H. (1971). Creativity and education. London: Routledge and Kegan Paul.

Matthews, M. (1980). The marxist theory of schooling: a study of epistemology and education. Sussex: Harvester Press.

Matthews, M. (1994). Science teaching: the role of history and philosophy of science. New York: Routledge.

Matthews, M. (1995). Challenging nz science education. New Zealand: The Dunmore Press.

Morris, E. (2002). Creativity in education. Speech presented at the national campaign for the arts/ national union of teachers creativity in education conference.

http://www.artscampaign.org.uk/campaigns/education/EMorris.html

NACCCE (1999). All our futures: creativity, culture and education, national advisory committee on creative and cultural education. London: DFEE.

Parnes, S. J. (1970). Education and creativity. In P. E. Vernon (Ed.), Creativity. Harmondsworth: Penguin.

Phillips, D. C. (1998). Coming to terms with radical social constructivisms. In M. R. Matthews (Ed.), Constructivism in science education: a philosophical examination. Dordrecht: Kluwer Academic Publishers.

Rowland, T. (2009). Geometry: Tales of elegance and love. In B. Sriraman and S. Goodchild (Eds.), Relatively and philosophically ernest: festschrift in honor of paul ernests $65^{\text {th }}$ birthday. Charlotte, NC: Information Age Publishing.

Rowlands, S. (2009). The importance of cultivating a meta-discourse in deliberate support of metacognition. In C. B. Larson (Ed.), Metacognition: new research developments. New York: Nova.

Rowlands, S., \& Carson, R. (2001). The contradictions in the constructivist discourse. Philosophy of Mathematics Education Newsletter, 14. http://www.ex.ac.uk/ PErnest/pome14/rowlands.htm

Rowlands, S. Graham, E., \& Berry, J. (2010). Problems with fallibilism as a philosophy of mathematics education. Science \& Education, online (and in print).

Skemp, R. R. (1976). Relational understanding and instrumental understanding. Mathematics Teaching, 77, 20-26.

Toulmin, S. (1967), The Philosophy of Science. First published in 1953. London: Hutchinson University Library.

Von Glasersfeld, E. (1995). Radical constructivism: A way of knowing and understanding. London: Falmer. doi: $10.4324 / 9780203454220$

Vygotsky, L. (1978). Mind in society. Mass: Harvard University Press.

Ward, T. B., Smith, S. M. \& Vaid, J. (1997). Conceptual structures and processes in creative thought. In T. B. Ward, S. M. Smith and J. Vaid (Eds.), Creative thought: an investigation of conceptual structures and processes. Washington DC: American Psychological Association.

Wittgenstein, L. (1974). Tractatus logico-philosophicus, (first published, 1922). London: Routledge and Kegan. Paul.

Wragg, E. C. (1999). An introduction to classroom observation, London: Routledge and Falmer. 